in time, and it was so regular that there was little donbt that the case presented the phenomena of a 2 to 1 heartblock. I sliow you tlie polygraph tracing (Fig. 1) in which

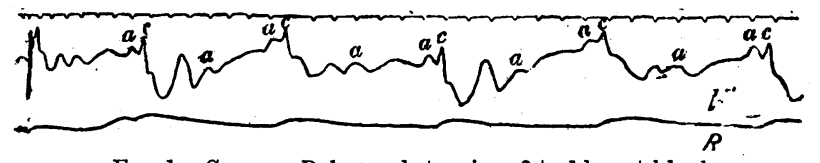

FIG. 1.-Case I. Polygraph tracing, 2 to 1 heart-block.

each wave marked $a$ is produced by the auricle which is contracting quite rhythmically; the wave $c$ is the com. municated wave produced in the carotid artery. A few
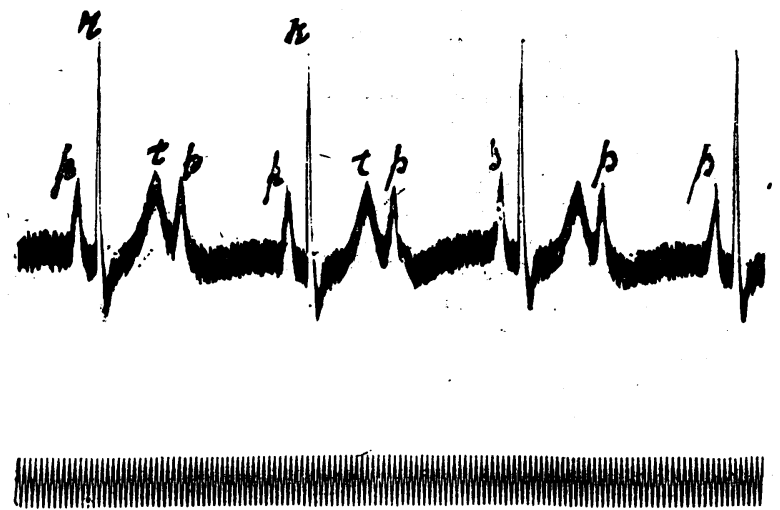

Fig. 2.-Case I. Electro-cardiogram, 2 to 1 heart.block.

days later the electro-cardiogram (Fig. 2) was taken, and you note that each wave $r$ which is near the commencement of the ventricular movement is preceded by two auricular contractions marked $p$. The diagnosis of a
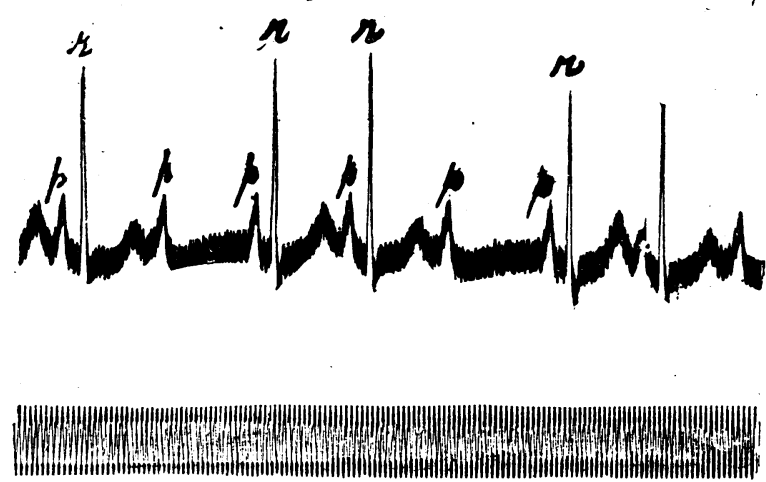

Fig. 3.-Case r. Alternate ventricular systoles preceded by two auricular systoles.

2 to 1 heart-block was thus confirmed. This patient's heart was improving, and even at the same séance as gave us Fig. 2, Fig. 3 was also obtained, and shows that only every alternate auricular systole $p$ was not followed by the ventricular wave $r$.

CASE II.-W., a man aged 60, with marked cardiac irregularity, showed in the neck to the unaided eye a confused succession of undulatory movements, in addition to the respiratory distensions and emptyings. The polygraph tracing from the neck and the radial artery (Fig. 4) gives the position of the communicated carotid pulsc

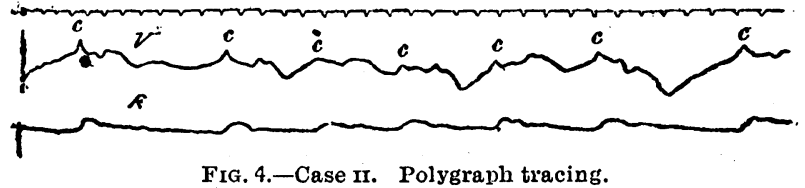

marked $c$, and you note there is an absence of the auricular wave present in the preceding tracings. In fact, there is no evidence here of rhythmic auricular systoles; there is practically what used to be called paralysis of the auricle, but is now known as auricular fibrillation: The electro-cardiogram (Fig. 5) bears out the diagnosis of extreme irregularity, the absence of a true
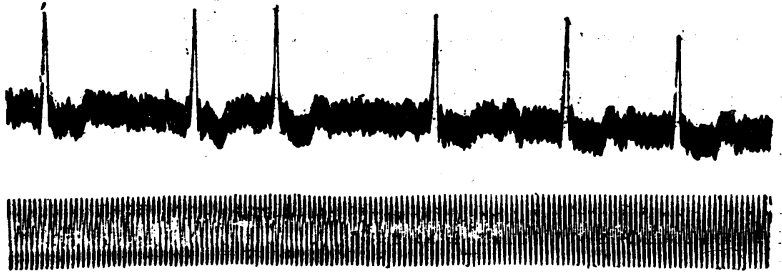

Fig. 5.-Case II. Electro-cardiogram, no auricle wave.

auricular wave, and the opinion that the patient had a fibrillating auricle.

CASE IIr. - S., a man aged 54 , with a systolic mitral murmur and a large heart, showed a ventricular systolic venous wave in the neck. The tracing (Fig. 6) shows the position of waves $a$ and $c$ as taken by the polygraph.

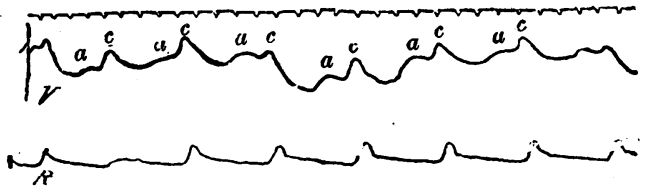

Fig. 6.-Case IrI. Polygraph tracing, in which the venous pulse seemed to be systolic.

The timing of visible venous pulsations is sometimes difficult, but in many cases ventricular systolic and auricular systolic waves can be separated, and their presence must be a measure of the fullness of the right side, especially of the right auricle.

I do not follow our subject further to-day, but you will understand that the study of the means by which the right side of the heart can be investigated, and the method of interpretation of the phenomena which I have pre. sented to you, are able to guide you to a true estimate of many a heart that will come under the consideration of some of you, probably in the near future. The matters I have dealt with lie at the foundation of a true understanding of overtaxed hearts.

\section{THE THEORY OF BLOOD PRESSURE MEASUREMENT}

With SPEctal Reference to the USE of Schemata aND Blood Pressure Instruments, TOGETHER WITH AX EXPLANation OF the Discordant Results arising FROM THE APPLICATION OF THESE INSTRUMENTS.

BY

LEONARD HILL, F.R.S., DIRECTOR, DEPARTMENT OF APPLIED PHYSIOLOGY, Y:D, EAL AND

JAMES M. McQUEEN, CaptaIN R.A.M.C.(T). RESEARCH FELLOW OF ABERDEEN ENIVERSITY.

THE study of blood pressure measurement has been of slow growth. The literature of the subject in past years shows how varying types of measuring instruments were employed, how the readings of systolic pressure obtained by them differed with the type of instrument; how with the same instrument discordant readings were obtained from arteries in different situations, where equality or something approaching to equality of reading might havo been expected.

Mucl attention has also been given to the fixing of the diastolic standard. Here also disagreements were to bo met with, disagreements both on the nature of the auditory and on the nature of the oscillatory index. Recent work, however, has made possible methods of accurately determining both the systolic and the diastolic pressure in the human subject.

Cousiderable progress, apart from the fixing of stanclards, has been made in the theory of blood pressure measure- 
ment. A wider linowledge of the factors involved now renders capable of explanation many of the difficulties and inconsistencies of blood pressure measurements. Let ris consider first the theory involved in the use of schemata in the elucidation of the phenomena of blood pressure measurement. Such schemata aim at the simplitication of the factors involved. The schemata used by Erlanger, by MacWilliam and his co-workers consisted of a compression chamber filled with water in which an artery was placed, and through this artery a flow of water was maintained under a pressure made to pulse from diastolic to systolic level. A constant peripheral resistance was arranged to impede the flow from the artery. In the latest schema used by Erlanger the resistance is infinite, and there is no flow.

Now all these schemata simplify the factors involved in blood pressure measurement, but they neglect a highly important factor which Flack, Hill, and McQueen liave diarvn attention to-namely, the necessity of providing a peripheral resistance which should increase pari passu with the increase of the compression pressure, thereby approximating closely to the physical conditions which pertain to the use of the armlet on the human being. By the provision of such a resistance Hill, Flack, and McQueen were able to explain the increase in the amplitude of the pulse tracing (known to clinicians) that is obtained from the radial artery at the wrist when the armlet is made to compress the upper arm with pressures varing from 0 - to just below diastolic pressure; they were also able to elucidate the mechanism of production of the $d u l l$ (Korotlioff) sounds which are heard on auscultation of the artery below the armlet. They showed that the pulse-wave passing under the compressing armlet was actually augmented as the compressing pressure rose from 0 - to just below diastolic pressure, and this augmented pulse-wave stretched the arterial wall beyond the normal, and so gave rise to those dull tension sounds which are heard when the compression is below the diastolic pressure. Thus, when Erlanger and MacWilliam simplify their schernata and make the peripheral resistance eitler a constant or an infinite resistance, they appear to us to ignore one of the most essential physical factor's involved, and lose thereby a knowledge of an essential part of the phenomenon of the Korotioff sounds-namely, the mechanism of the production of the dull sounds.

It has been found by Flack, Hill, and McQueen that in their schema, with a properly contrived peripheral resistance, the systolic pressure is accurately measured by that pressure which obliterates pulsation (felt in a piece of artery placed beyond the compression chamber), and that diastolic pressure can be no less accurately measured either by the auditory method (sudden diminution of sound) or the oscillatory method (maximal pulsation). MacWilliam, using his imperfect schema, failed to get agreement between the auditory and oscillatory indices. The compression in all forms of schemata used by the different workers is a fluid one and so equally applied all round the artery placed within the compression chamber. Accordingly the assumption is made that such schemata more or less accurately resemble the conditions of an armlet placed round the upper arm wl:ea compression is applied.

One is led to believe that the tissues, muscles, tendons, etc., which lie in relation to the brachial artery transmit the pressure precisely as the fluid round the artery in the compression chamber. However, it was exactly on this point that older writers had their doubts. Tiegerstedt called attention to the possibility of a loss of pressure in transmission through varying integuments. The same idea is still to be noted in Erlanger's recent paper on the mechanism of the oscillatory criteria. Here, then, we must consider these questions: Do the tissues transmit pressure like water? Loes a muscle with an elastic mem. brane surrounding it transmit pressure precisely as water? Or do the muscles, tendons, connective tissue transmit pressure but imperfectly, and are all our measurements more or less approximations?

Let us analyse more closely the factors involved in a circular compression chamber. One may state that the pressure nust not merely be clelivered equally all round the artery, but, what is equally important, the fluid or air, if air be used, must be capable of being moved with each pulsation-that is, the compressing pressure must be applied in a vibratory manner, and the periodicity of its vibration must be the periodicity of the pulse.

If the compression pressure be rigidly applied the whole schema fails. This was shown to be the case by Flack, Hill, and McQueen, and was brought out again later when the compression tube was applied to the femoral artery in certain animal experiments carried out by Erlanger. $\mathrm{He}$ notes that the Korotkoff sounds always disappear when the closing of the stopcock, which renders his arteriograph more rigid, catches the pulse in the diastolic phase. In other words, a circular compression chamber of a pressure above diastolic, made rigid at the moment of diastole, holds the artery closed during the entire pulse cycle. It is quite obvious that it should do so, because the pulse must simply beat against the walls of an artery compressed and deformed into a flattened shape, while in diastole, and then surrounded by a rigid medium. An artery, if it is to expand during the pulse pressure phase, must expand by virtue of its power to move the whole compressing medium.

Accordingly those who use a schema with compression chamber to determine the phenomena involved in the estimation of systolic and diastolic pressure must use a schema which permits of the compression being applied in such a way that it can yield and be pulsed, or, to use the terminology of Erlanger, the medium in the chamber must have a sufficient amount of "compressibility."

Hill, Flack, and McQueen and Ingram first drew attention to this phenomenon in their study of arteries placed superficially and resting on bone-for example, the dorsalis pedis, temporal, or the aberrrant radial artery. When the bag of Hill's pocket sphygmometer was placed on an aberrant radial artery at the back of the wrist or on the dorsalis pedis, a systolic reading of, say, 40 to $45 \mathrm{~mm}$. of $\mathrm{Hg}$ was obtained. The artery was deformed at pressures below diastolic pressure, and as the compressing medium, the bag, was not capable of being transformed into a vibrating or compressible pressure by the beat of the aberrant radial artery alone, or by the dorsalis pedis alone, the pulse ceased to pass below the bag. On the other hand, when an armlet was placed over the aberrant radial artery at the back of the wrist so that in addition it embraced the pulsing tissues of the forearm on the front of the wrist, the reading rose to 110 or $115 \mathrm{~mm}$. of mercury, a close approximation to the real systolic pressure. When, on the other hand, the front of the forearm was encased in a wooden groove, and the armlet put on outside this, so that pressure of the armlet could be anplied on the aberrant radial artery, but ceased to be under the influence of the pulsing tissues of the front of the forearm, the reading fell to 40 or $45 \mathrm{~mm}$. of $\mathrm{Hg}$, a precisely similar reading to that obtained by Hill's bag.

In the one case the artery is deformed by the compres. sion from the circular into the oval or flattened shape, and the frictional resistance to the passage of the pulse wave is thereby so increased that the pulse spends its force in dilating the elastic wall of the artery above the point of compression, and does not pass through. In the other case the veins and capillaries are compressed so that blood cannot be expressed, and the whole mass of blood vessels in the compressed area becomes filled with blood, which pulses, and the artery lieeps its circular form, and cannot be deformed until the compression rises above the systolic pressure.

It is obvious that the blood flow is not absolutely stopped at any pressure under systolic. It continues to escape from the veins as the systolic pressure in the mass of compressed tissues overcomes the pressure of the com. pressing armlet, the capillary channels becoming all filled to distension. The tissues under the armlet become comparable to the brain enclosed in the skull, where, with each arterial pulse, an equivalent venous escape takes place.

The necessity of applying compression so that the whole mass of tissue vibrates with the pulse was first emphasized by Hill, Flack, and McQueen. To use the terminology employed by them, at each beat of the pulse the compressing bag or armlet must be lifted off tho artery; the damper must be a vibrating damper if true systolic readings are to be obtained.

When the armlet embraced the aberrant radial artery together with the whole forearm, the pressure in the armlet became a vibrating pressure vibrated by the pulse 
which affects the whole mass of tissue in the front of the forearm, all the vessels of which mass are filled with blood. When, on the other hand, an artery lies on bone and is alone compressed by the armlet or Hill's bag, the artery, per se, is powerless to lift the armlet or bag at each pulse the pulse strikes the artery deformed near diastolic pressure and fails to pass through.

The conditions are precisely similar to those produced by Erlanger when he closed the stopcock of his schema during diastole, and at the same time made rigid the rubber membrane of his apparatus. The action of the simultaneous pulse of all the ressels in the mass of tissue compressed by the armlet or bag in pulsing the armlet or bag off the artery, thereby rendering the whole compressing system compressible, Flack, Hill, and McQueen designated by the term "resonance."

It was shown that when a pressure in the armlet was raised by, say, $10 \mathrm{~mm} . \mathrm{Hg}$, those veins under the armlet with an internal pressure lower than $10 \mathrm{~mm}$. of $\mathrm{Hg}$ were compressed, and the whole capillary area rose to $10 \mathrm{~mm}$. of $\mathrm{Hg}$ pressure. So with each increment of pressure in the armlet an equivalent rise of pressure in the capillary system took place, so long as the systolic pressure of the artery supplying the capillary area was not overtopped and the artery shut up. Consequently the pressure that an armlet exerts on the mass of tissues is obtained through the compression of the veins, and the mass of blood con. gesting in the tissues through the compression of the veins transmits the pressure to the artery. Here one has the counterpart of the fluid in the schema, and the pulsing beat of the mass lifts the armlet off the artery precisely as the mass of fluid surrounding the artery in a schema, constructed of suitable resilience, is lifted by each beat of the artery. In the case of the schema the artery by its pulse moving the arterial walls transmits their vibration to the compressing mass of fluid. In the case of the armlet the pulse in the main artery passes into all the arteries and arterioles of the mass of tissue embraced by the armlet, and it requires the sum of all these arterial pulsations to vibrate the armlet, or, to use the terminology of Erlanger, to rencler the armlet "compressible." The experimenter arranges his schema so that the artery'enclosed is fully capable of moving the compressing mass around it. But when an armlet is used, it is found that the main artery alone is insufficient, and that the throb of the whol.. mass of tissue enclosed is required.

There is one essential condition to be complied with before a blood pressure instrument can measure accurately. It is obvious that it must be broad enough to compress a sufficiently large area of veins, and so embrace a sufficiently large enough pulsing area around the artery.

The first blood pressure instrument devised by Herissart conformed to that requirement. The bag or capsule as pictured by him was broad. Succeeding inventors, endeavouring to improve the instrument in portability or neatness, diminished the size of the bag, with resulting inaccuracy.

When a small bag is applied to an artery it closes the veins underneath it; but owing to the multiplicity of lateral connexions in the vascular system, the veins and capillary system pressed on are obliterated, through the blood escaping by these collateral channels. Similarly, the physician who places his finger on the radial artery (with, say, a systolic pressure of $130 \mathrm{~mm}$. of $\mathrm{Hg}$ in it) deforms the artery at a pressure of, perhaps, no more than $40 \mathrm{~mm}$. of $\mathrm{Hg}$, and if the systolic pressure were $200 \mathrm{~mm}$. of $\mathrm{Hg}$, his finger would deform the artery at $70 \mathrm{~mm}$. of $\mathrm{Hg}$ or so, depending not on the height of systolic pressure but on that of the diastolic pressure. Consequently, his estimation of changes in blood pressure in an artery is only relative; the range through which he appreciates rises of pressure is limited, and his reading of change of systolic level really dopends on whether the diastolic pressure is raised correspondingly to the rise of systolic pressure. The finger of the plyysician easily deforms the artery into the oval or flattened shape, and so prevents the pulse from passing, because the area of veins compressed by the finger is totally inadequate. There is no mass of pulsing tissue under the finger, and the finger becomes a rigid damper.

In a blood pressure measuring instrument, then, the area of the compressing bag or armlet must be adequately broad to compress sufficient veins, so that tho blood is congested under the bag or armlet and the pulsation of the mass of tissue is secured.

Instruments such as Oliver's haemodynamometer, with a small pad placed on an artery from which systolic and diastolic pressures aie obtained by an oscillatory index, fail because the pad is not broad enough. They deform the artery, as the finger does. The bag of Hill's pocket sphyggmometer, on the other hand, is made large enough to compress the whole of the forearm; the hand enclosing the bag compresses the back of the wrist. Here we have the explanation of many of the discordant readings in tho literature of blood pressure measurement. 'The instruments varied in the breadth of the area which compressed the veins.

There remains to be considered the discordant readings obtained with the same instrument on different sites. It was pointed out by Tiegerstedt that readings of the systolic pressure in the temporal artery varied greatly from those of the radial artery taken with the same instrument. Loss of pressure due to the corering tissues in the case of the radial artery was called in to explain the discrepancy. Thiat false idea-of an obstruction which the tissues place in the way of accuracy in blood pressure measurement-runs through most of the literature and still persists. Now when the instrument was applied to the temporal artery, where it lay exposed on bone, the reading was certain to be erroneous and too low. In fact, the reading would be exactly comparablc to the aberrant radial artery or dorsalis pedis. Here we have no mass of tissue surrounding the artery, where with the simultaneous compression of the veins a pulsing mass conld be developed around the artery. Consequently, if the instrument used were broad the readings from the radial and from the temporal artery must differ. But where the instrument had a narrow bag or pad, the readings of the radial artery and the temporal artery would approximate, and both would be equally erroneous. Because with a narrow pad or bag the tissues surrounding the radial artery, though there to be utilized, could not be brought into play.

Consequently, readings bccome accurate, not because pressure can get at an artery without loss through tissues, but because when sufficient tissues, and these amply supplied with blood, are embraced under the compressing pressure, the pulse of the congested tissues enables the compressing pressure to be a resilient pressure and not a rigid pressure, and prevents continuous deformation of the artery until the systolic pressure is overtopped. Flack. Hill, and McQueen showed that when all the vessels of the forearm are dilated by heat, while those of the upper arm are constricted by an ice-bag, then the artery in the upper arm is obliterated by a lower armlet pressure than it is in the forearm. They thus demonstrated the importance of the blood in the tissues by a conclusire experiment.

When one turns to the consideration of auscultatcry indices, the same laws apply. Using Hill's bag on the aberrant radial artery (where it lay on bone) sounds were heard, but not sounds similar to Korotkoff's sounds. The level of pressure and the range of pressure at which sounds occur were all erroneous. The diastolic index was absurdly low and the systolic index was 40 or $45 \mathrm{~mm}$. of $\mathrm{Hg}$, because the artery was deformed and held deformed by the rigid pressire. When the armlet was applied to the aberrant radial and the front of the forearm was enclosed in the wooden groove so that the armlet did not come under the influence of the pulsing tissues, the Korotkoff readings were exactly the same as with Hill's bag and wrong.

When the armlet rwas made to embrace the forearmthat is, the mass pulsing tissues-the readings in tho aberrant radial rectified themselves.

Consequently, when Erlanger writes, "Views assigning prime significance to the tissues surrounding the artery are invalidated by the fact that the bare artery suffices for the production of characteristic sounds," his argument is fallacious. The bare artery under the armlet or under Hill's bag neither gives the characteristic Korotkoff's sounds nor does it suffice to indicate systolic and diastolic pressure. It produces sounds the whole range of which appear below diastolic pressure.

The sounds which Erlanger succeeded in hearing in the isolated artery he obtained by compressing the artery 
circularly with fluid, and after carefully arranging that the size of the arteriograph and its compressibility were guch that it was within the power of the artery to pulse the whole compressing mass of its walls.

Erlanger does not seem to realize that what makes the armlet on the upper arm as "compressible" as his arteriograph is not the beat of the brachial artery alone, but the simultaneous throb of the whole mass of tissues below the armiet.

Further, the genesis of Korotkoff's sounds owe their fundamental origin to this mechanism brought into play by the compression of the surrounding tissues. Erlanger states: "Hill, Flack, and McQueen maintain, without offering any experimental evidence for their view, that the compressing armlet converts the compressed area of the arm into a resonating mass; the pulse is not damped down in the labile arteries, but strikes the blood, which fills to distension, not only the main artery, but every patent arteriole throughout the mass, and causes the whole tense mass to vibrate."

It is difficult to believe that Erlanger has followed the series of researches of Hill, Flack, and McQueen. In their work they show how the veins are compressed and the peripheral resistance rises as compression of the armlet rises; how this rise in pressure stretches the arterial wall and produces the dull sounds; how the blood is con gested in the mass of tissues under the armlet. Con sequently; through this action of the armlet on the tissues, both under it and beyond it, each pulse strikes the blood, and the arterial wall experiences an additional strain as the kinetic energy of the flow of blood meets the obstacle of contained blood in front of it. Erlanger describes this phenomenon as water hammer, but the use of this term brings out no new idea to that already demonstrated by Hill, Flack, and McQueen.

We conclude, then, that-

1. To give accurate information on the factors concerned in blood pressure measurement, a schema must permit of compression being applied to an artery in a pulsable and not rigid manner, and a rise of peripheral resistance pari passu with increasing compression must be arranged for.

2. When an armlet or bag of Hill's pocket sphygmometer is made to compress an artery where it lies on bone with little tissue round it-for example, temporal, dorsalis pedis, aberrant radial-it deforms the artery and prevents the passage of the pulse at a pressure less than diastolic. The finger of the physician acts in the same way, and therefore cannot estimate the systolic pressure accurately.

3. Compression of the tissues surrounding the artery so as to block the venous outlets is essential to accurate blood pressure measurement. This congests the blood beneath and beyond the armlet or bag. The pulsing of the congested mass of tissues renders armlet or bag capable of delivering a circular compression to the artery, and one which yields to the pulse and prevents deformation of the artery until the systolic pressure is overtopped.

4. Sufficient area of veins must be blocked if the blood pressure instrument is to be an accurate one, consequently the bag or armlet must be broad. The bag, together with the observer's hand, enclose the forearm, and so makes the bag of Hill's pocket instrument equivalent to the armlet. Failure to make the bag bioad accounts for many inconsistencies in the literature of blood pressure measurement.

\section{REFERENCES}

Studies in Blood Pressure Estimations by Indirect Methols, I and II, by Joseph Erlanger, Amer. Journ. of Physiol. vol. xxxix, No. 4 February, 1916; vol. xl, No. 1, March, 1916. Hill, McQueen, and Flack: Proc. Roy. Soc., B, vol. Ixxxvii, p. 344, 1914, and vol. Ixxxviii, p. 517, 1915. MacWilliam and co-workers: Heart, vol. v, p. 153, 1914, and vol. iv, p. 393,1913 .

For some years rabies had decreased in France almost to vanishing point. Owing to the large number of dogs which since the war have taken to a wandering life and thus escape police control, there has been a considerable recrudescence of the disease in many departments. The number of persons bitten by dogs suspected of rabies and treated at the Paris Pasteur Institute was 373 in 1914 and 654 in 1915. In 1916, from January 1st to May 13th, it was 420; this figure, if the same rate of progression is maintained, will give a total of more than 800 for the whole year. On June 9th the Paris prefect of police issued an order that in the strects all dogs must be led in a leas? or muzzled and have a collar bearing the name and address of their owner.

\section{THE SYSTOLIC PRESSURE IN ACUTE NEPHRITIS.}

\section{BY RODOLPH G. ABERCROMBIE, M.D.,} Temporary Captain R.A.M.C.

I HAVE recently treated at a base hospital in France several hundred cases of nephritis occurring amongst the soldiers of the Expeditionary Force, and have taken advantage of the opportunity thus afforded for the study of the blcod pressure during the acute phase of this disease.

The characters of war nephritis have already been described ${ }^{1}$ here it may be said that it presents the usual features of an acute nephritis of moderate severity, and that, as in other forms of acute nephritis, the blood pressure appears to be always raised at some period during the course of the disease.

\section{Duration of Elevation of Pressure.}

In cases of average severity the pressure was usually raised for a period of from five to ten days after the patient's admission to hospital; not infrequently, however, the elevation persisted for several weelss, so that the patients were transferred to England with the pressure still high.

\section{Range of Systolic Pressure.}

Daring the early stages the systolic pressure usually ranged between 135 and $180 \mathrm{~mm}$. Hg; exceptionally, and particularly in association with convulsions, it reached 200 or 210. The pressure was thus lower than that usually seen in chronic nephritis; indeed, a pressure of over 200 was found to be presumptive evidence that the disease was really of long standing.

\section{Diurnal Variations in Pressure.}

A striking feature was the wide diurnal variation which often occurred between the morning and evening blood pressures. Just as in certain diseases there is a wide difference between the morning and evening temperatures, so in this form of nephritis some agent appears to be at work which causes an evening rise of blood pressure and a morning fall the difference between $t h \theta$ morning and evening presgures may be 20,30 , or even as much as $60 \mathrm{~mm}$. H (Chart 1 and Chart 2).

All the charts here repro. duced show the systolic pressure taken twice daily, namely at 10 a.m. and 6 p.m., and. recorded in millimetres of mercury. The palpatory method was used, witl the patient

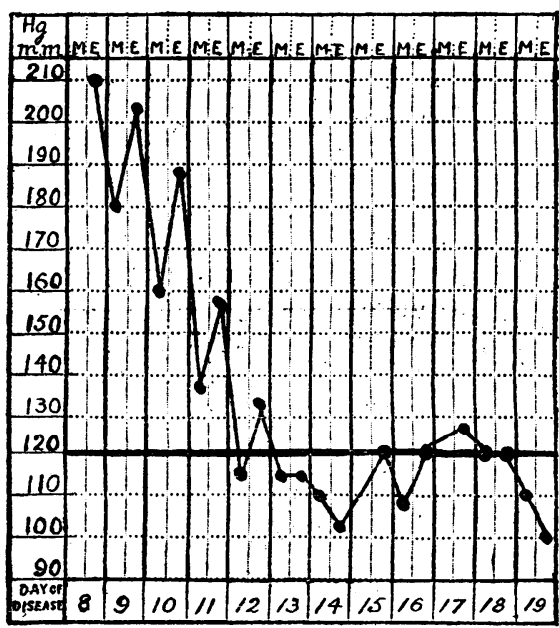

Chart 1.-Systolic pressure, taken twice daily at 10 a.m. and 6 p.m., and recorded in millimetres of merury "Stairease"descent. recumbent; a tambour sphygmomanometer (Tycos) was employed.

If Charts $1,2,3$, and 4 be examined, it will be noticed that had the morning blood pressure alone been recorded, a totally erroneous idea of the course of the pressure would have been obtained; indeed the chart would have been as misleading as the temperature chart of a case of tuberculosis upon which only the morning temperatures were shown.

When the blood pressure was falling from day to day, it usually did so in a series of morning remissions and orening rises, thus forming a descending "staircase" 